2019-03-29

Risk balancing through selective use of social and physical information: a case study in the humbug damselfish

Kent, MIA

http://hdl.handle.net/10026.1/14452

\begin{abstract}
10.1111/jzo.12669
Journal of Zoology

Wiley
\end{abstract}

All content in PEARL is protected by copyright law. Author manuscripts are made available in accordance with publisher policies. Please cite only the published version using the details provided on the item record or document. In the absence of an open licence (e.g. Creative Commons), permissions for further reuse of content should be sought from the publisher or author. 


\title{
Risk balancing through selective use of social and physical information: a case study in the humbug damselfish
}

\author{
M. I. A. Kent ${ }^{1}$ iD, A. L. Burns ${ }^{1,2}$ (D) W. F. Figueira ${ }^{1}$ (D) G. P. F. Mazue ${ }^{1}$ (D) A. G. Porter ${ }^{1}$ \\ A. D. M. Wilson ${ }^{1,3}$ (ID) \& A. J. W. Ward ${ }^{1}$ \\ 1 School of Life and Environmental Sciences, University of Sydney, Sydney, NSW, Australia \\ 2 Taronga Conservation Society Australia, Mosman, NSW, Australia \\ 3 School of Biological and Marine Sciences, University of Plymouth, Plymouth, UK
}

\begin{abstract}
Keywords
risk balancing; predation risk; coral reef; Dascyllus aruanus; refuge; 3D modeling; social environment; risk perception.
\end{abstract}

\author{
Correspondence \\ Maud I. A. Kent, School of Life and \\ Environmental Sciences, University of Sydney, \\ Heydon-Laurence Building (A08), Sydney, NSW \\ 2006, Australia. \\ Email: maud.kent@sydney.edu.au \\ Editor: Jean-Nicolas Volff
}

Received 15 October 2018; revised 31 January 2019; accepted 5 March 2019

doi:10.1111/jzo.12669

\begin{abstract}
To effectively balance the need to forage against the need to avoid predation, animals should utilize information from both their physical and social environments. However, most studies have considered these factors in isolation and few have investigated how animals change the use of these cues temporally. Using novel 3D modeling of the environment and 3D observations of fish movement, we investigated how local abiotic and biotic features of the environment, along with tidal patterns, impacted risk-related behaviors using humbug damselfish, Dascyllus aruanus, in coral reef habitats as a model system. We found that damselfish balance risk by utilizing cues from both the physical and the social environment, although the relative importance of these cues changes according to tide. At flowing tide, when food resources are typically more abundant, damselfish increased their foraging behavior, but only when their external social environment offered protection from predation. At slack tide, when food resources are typically less abundant, damselfish were not responsive to their external social environment. Regardless of tide, damselfish living in smaller corals showed more risk-averse behavior, emphasizing the importance of local refuge availability on risk perception. Our results underscore the flexible use of social and physical information along temporal scales and how both biotic and abiotic features influence the trade-off adopted between foraging and refuging behavior.
\end{abstract}

\section{Introduction}

One of the greatest challenges for animals is balancing the need to forage against the need to avoid predation. Often, these imperatives are mutually exclusive, with foraging behavior exposing an animal to increased predation risk and predator avoidance behavior reducing the amount of time available for energy acquisition (Metcalfe \& Furness, 1984; Godin \& Smith, 1988). However, the risk of engaging in foraging behavior changes with different physical and social aspects of the environment, and along different temporal and spatial scales. Therefore, in deciding when and where to forage, individuals should consider the likely payoff of engaging in these behaviors against the risk of predation, a concept referred to as the risk-reward trade-off (Lima \& Dill, 1990).

Studies have shown that animals assess risk based on both the physical and social aspects of their surroundings. For instance, animals utilize characteristics of the physical environment, such as substrate color or habitat complexity, to determine how easily they can detect predators (Metcalfe, 1984), find refuge (Cowlishaw, 1997) or remain camouflaged (Powolny et al., 2014). While less complex environments may increase visibility and promote early predator detection, they often contain fewer refuges and have been linked to higher prey capture rates (Longland \& Price, 1991). A study by Golub, Vermette \& Brown (2005) found that habitat complexity modified risk perception in sunfish, Lepomis gibbosus, which increased antipredator behavior when in more complex environments, suggesting more risk-sensitive behavior when visibility is reduced.

The perception of risk can also shift with the social environment. In large groups, many eyes enable early predator detection (Siegfried \& Underhill, 1975; Boland, 2003) and collective defense, dilution and confusion effects reduce an individual's per-capita risk (Krause \& Ruxton, 2002; Ward \& Webster, 2016). Consequently, individuals in large groups often spend less time vigilant and more time foraging (Lima, 1995; Beauchamp, 2008; Creel, Schuette \& Christianson, 2014) and show signs of reduced risk perception compared to solitary individuals (McDonald et al., 2016). Although these benefits are often limited to groups of conspecifics, these benefits can extend to mixed-species assemblages, especially when heterospecifics share predators (Goodale, Beauchamp \& Ruxton, 2017). Therefore, the behavior of both the immediate 
conspecific environment and the wider heterospecific environment can act as an alarm system to alert when predators approach (Heymann \& Buchanan-Smith, 2000).

Despite all the evidence that both physical and social factors shape an animal's perception of risk, there is a lack of research that considers these factors simultaneously or whether the use of these cues shift in temporally variable environments. Recent work on eastern chipmunks, Tamias striatus, found that vigilance behavior increased in riskier environments, as shaped by reduced habitat complexity and high-wind conditions, which makes auditory detection of predators more difficult. Importantly, they found that this risk perception and vigilance behavior were modified by the social environment, with neighbor density amplifying antipredator behavior, rather than reducing it (Clermont et al., 2017). While this study provided evidence that both physical and social aspects are important to understanding what shapes animal behavior, less is known about how or whether animals adjust the use of each factor to temporally variable conditions.

In marine habitats, behavior can change with the tidal patterns that drive predictable fluctuations in predator and prey abundances. For instance, humbug damselfish (Dascyllus aruanus) increase their foraging activity to coincide with the greatest availability of plankton during high tide (Forrester, 1991) and prioritize foraging over antipredator behavior when the payoff for foraging is greatest (Hansen, Morrell \& Ward, 2016). This underscores the need to consider temporal scales, such as tidal cycles, when investigating the factors shaping behavior.

The question remains as to how animals balance risk along social, physical and temporal scales. The humbug damselfish (D. aruanus) provides an interesting case study for this riskreward trade-off. This species is an obligate planktivore that forms stable, restricted-entry social groups (hereafter 'colonies') ranging between 2 and 25 individuals, which associate closely with branching acroporan or pocilloporan coral species (Coates, 1980a,b; Forrester, 1991; Sale, 1971). As small reef fish, damselfish are vulnerable to predation from a wide range of predators throughout the reef environment. However, by living in social groups and by retreating into their branching coral heads when predators approach, damselfish can mitigate some of these risks (Coates, 1980a,b). Given the patchy distribution of suitable branching corals throughout the reef, the external environment can differ greatly between colonies. Importantly, as humbug damselfish rarely venture further than $1 \mathrm{~m}$ from their home corals (Sale, 1971), their behavior is a direct reflection of their immediate environment.

Although previous work has shown an ability to respond adaptively to time of day (Burns, 2016), tide and group size (Hansen et al., 2016), no study to date has investigated how the physical environment, such as the surface area (SA) of their home coral and the complexity of the surrounding environment (factors that affect the availability of refugia) affects risk perception. In complex reef environments, damselfish behavior is likely shaped by both their local group size as well as their external social environment, which can contain both transient and resident heterospecifics and conspecifics.

This study examined the effects of four factors on the foraging and refuging behavior of humbug damselfish: (1) focal coral complexity (measured as both SA and rugosity), (2) surrounding habitat complexity (3) local social environment (colony group size) and (4) external social environment (number of other fish in proximity to the focal colony). Given the previously described effect of tide on the behavior of these fish, we hypothesized that a greater proportion of the colony would emerge at high tide when food is more available, and that the proportion of the colony emerged would increase with the size of the colony and the number of ecologically similar fish in the surrounding environment. We also hypothesized that larger focal corals, and greater surrounding habitat complexity, would reduce risk perception through decreased competition for refuge, resulting in greater emergence. Using video recording and novel 3D mapping techniques, this study aims to investigate how the risk-reward trade-off is shaped by the social and the physical environment and whether this changes with tide.

\section{Materials and methods}

Research was conducted within the 1st lagoon at One Tree Island Research Station on the Great Barrier Reef from 2 October to 8 October in 2017 between the hours of 9 am and $12 \mathrm{pm}$. As all colonies were located within the same shallow lagoon, tidal fluctuations, plankton availability and relative risk would have been qualitatively similar across all colonies. We chose to collect data during the morning to limit any effect that time of day may have on humbug damselfish behavior (Helfman, 1986; Burns, 2016). For this study, snorkelers only selected colonies that were more than $2 \mathrm{~m}$ apart to ensure spatial independence (Sale, 1971) and groups containing more than three individuals and fewer than 24 individuals. No other criteria were used to select colonies. Once suitable colonies were selected, snorkelers recorded time of day, tidal state and began filming damselfish behavior.

Each colony was filmed once for a period of $20 \mathrm{~min}$ using two GoPro Hero 3+ cameras placed $1 \mathrm{~m}$ away at approximately $90^{\circ}$ to one another. Recording of damselfish from two angles facilitated observation of individuals in 3D space and minimized occlusion. Each camera recorded $24 \mathrm{fps}$ at a wide angle setting and at a resolution of $1080 \mathrm{dpi}$. After the 20-min filming period, two snorkelers located $5 \mathrm{~m}$ to either side of the focal colony independently but simultaneously performed a fish census, including species identification and counts for $2 \mathrm{~min}$, considering all fish within a 2-m radius of the focal colony (following methods outlined in Hansen, O'Leary \& Ward, 2017). Where records differed, the average of the two estimates was taken, or the greater estimate where accounts differed by only one individual or species was taken. These counts were then grouped into three categories namely: nonfocal resident mid-water species, non-focal resident benthic species and nonresident mid-water species (see Table S1). These categories were created due to the expectation that damselfish would respond more strongly toward fish of similar size and ecology, specifically mid-water residents compared to benthic residents, and that the response may differ based on whether fish are local or transient within their environment. In this study, we made a distinction between the local social 
environment (i.e. immediate colony group size) and the external social environment.

After this 2-min census period, snorkelers recorded time of day and, using tidal schedules, whether the tide was flowing or slack. These tidal categories were selected because damselfish feed on zooplankton in the water column, meaning that local currents impact food availability (Russo, 1977). Given that the lagoon curtails full tidal cycles, slack tides occurred when the water level fell below the perimeter of the lagoon $(<1.7 \mathrm{~m}$ above low tide sea level). Once these measures were taken, a third snorkeler mapped each focal colony and the surrounding substrate following Figueira et al. (2015). The snorkeler placed three calibration targets within $2 \mathrm{~m}$ of the focal colony and took between 700 and 1500 photos using three GoPro cameras spaced evenly along a $1-\mathrm{m}$ pole capturing HD photos at $1 \mathrm{fps}$, 1080 dpi. Two of the calibration targets consisted of two flat disks printed with unique black and white patterns and connected by a flat metal weight. The third target had three metal bars of equal length connected at $90^{\circ}$ angles. Two of the bars lay flat along the substrate and had flat disks printed with unique black and white patterns attached to the ends. The third arm sat perpendicular to the ground and had a cap with a black dot in the middle (See Fig. 1). Throughout the week, we collected data on a total of 55 different damselfish colonies.

\section{Behavioral analysis}

For each colony, both video recordings were uploaded to VirtualDub where they were synchronized by eye, placed side-byside and exported as a single video file. After the videos had been scanned to get an accurate measure of damselfish group size, the positions of the damselfish relative to their home

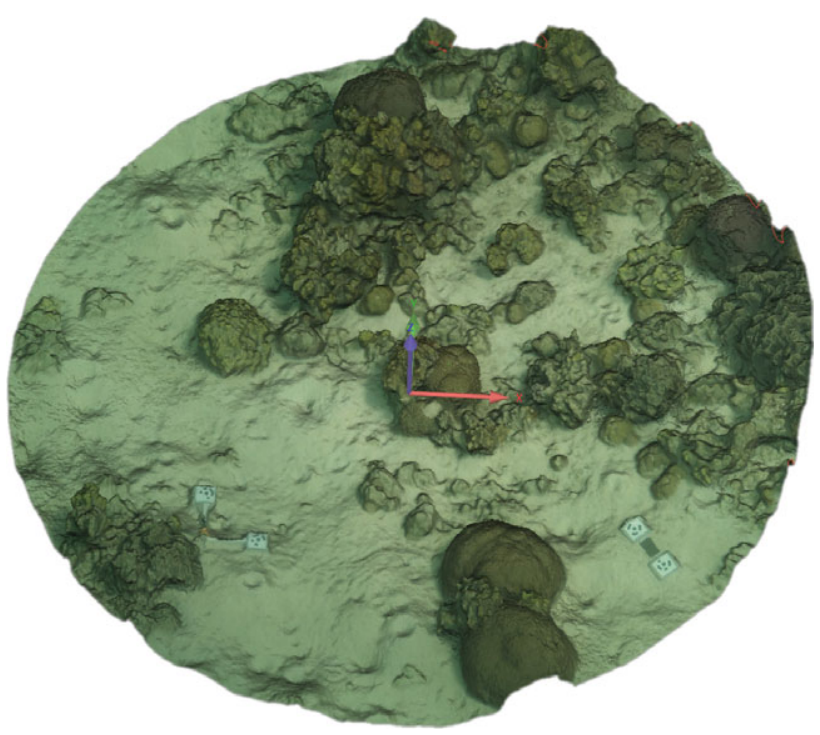

Figure $13 \mathrm{D}$ model of a damselfish colony. Each mesh was $3 \mathrm{~m}$ in diameter with the focal coral at the center. Two of the targets used to orient and calibrate the mesh can be seen in the bottom right and bottom left of the model. For the target on the right: the black dots at the center of each black pattern are $250 \mathrm{~mm}$ apart. coral were recorded every $20 \mathrm{~s}$ over a 10 -min period. A damselfish was considered to have entered the coral when they were within one body length of the nearest edge of the coral, estimated by eye. We recorded positions every $20 \mathrm{sec}$ to reduce the autocorrelation between measures taken over time. All behavioral observations were carried out by the same researcher to ensure consistency. From these counts, we calculated the median proportion of the group outside the focal coral over the 10-min observation period. Because damselfish behavior is bimodal, with fish limited to either foraging in the water column or retreating inside when they perceive danger (Hansen et al., 2016), quantifying the proportion of the colony outside of the coral head is a relevant measure of risk perception in this species.

The 10-min behavioral observation period did not begin until all snorkelers were out of the field of view of both cameras and a 5-min acclimation period had elapsed. This 5-min acclimation period was chosen to maximize time between turning on and turning off the camera, though damselfish resume normal behavior after $1 \mathrm{~min}$ (personal observation). On one occasion, the cameras stopped recording before the 10-min period had finished so the acclimation period was reduced to 2 min to allow a 10-min observation period. The proportion of fish within the coral during these 10-min did not differ when a full 5-min acclimation period was given and only 7-min of damselfish behavior was observed.

\section{D meshes}

To calculate the complexity of the focal coral and surrounding habitat, we created 3D models of each damselfish colony and the local environment within $1.5 \mathrm{~m}$. This was done using the software package Photoscan Professional v1.3.5 (AgiSoft LLC, St. Petersburg, Russia) following methods developed by Figueira et al. (2015). We began by uploading the photos of each colony into Photoscan Professional, which aligned these at the highest settings with no pre-pair selection by identifying common features of the environment. Once the photos were aligned, the program generated a sparse point cloud in $3 \mathrm{D}$ space, which served to reconstruct the path along which all the photos were taken as well as the orientation of each camera. This information was then used to populate the sparse point cloud with additional points, generating a dense point cloud, which led to the creation of a continuous 3D mesh of threesided polygons. Agisoft then used the original images to insert color and texture into each model. These finalized models were calibrated using each of the three targets, which were detected automatically by the program. The 3-pronged target was used to orient the mesh along $x, y, z$ axes to match real-world coordinates. This process of calibration led to error estimates, which indicate the accuracy of our 3D models.

Each model was exported as an.obj file and cropped to a 3-m diameter circle centered on the focal colony using Geomagic Studio (3D Systems) (Fig. 1). The SA $\left(\mathrm{m}^{2}\right)$ of these cropped models was measured, then focal corals were cut out using color and texture to differentiate between focal coral species and external substrate. These clipped focal meshes were used to calculate focal coral SA (hereafter focal coral size). To 
create a measure of only surrounding habitat complexity, we subtracted the SA of the focal coral from the SA of the full cropped model. Focal and non-focal habitat complexity was measured using SA and rugosity, a measure of complexity in which real SA is divided by geometric SA. We also considered both focal coral size and local habitat complexity as separate measures given the high-site fidelity and reliance on their focal coral rather than external environment for protection. Given previous research finding that damselfish rarely venture further than $1 \mathrm{~m}$ from their focal coral, we measured local habitat complexity within a 1-m radius of the home coral.

\section{Statistical analysis}

When colonies were in very shallow water and photographed on clear days, the sun caused extensive dappling, which prevented Agisoft from aligning photos and constructing 3D models for five of our sites. Our final analysis therefore included 50 colonies, 25 of which were recorded at slack low tide and the remaining 25 at flowing tide. To ensure that the physical and social aspects did not significantly differ between colonies recorded at slack tide and flowing tide, we used independent student $t$ tests on log or square-root transformed variables to meet the assumption of normality and equality of variances.

To investigate how each physical and social aspect of the environment influenced damselfish behavior, we ran a beta regression on a model of social and physical factors against proportion of the colony outside the coral (see Table 1 for model factors). To investigate how tide might affect the importance of each social and physical factor, we also included an interaction between each factor and tide within the larger beta regression. Where there were significant interactions with tide, we ran smaller beta regressions within tide datasets to quantify the relationship between the factor and proportion of colony emerged. These smaller models were created by selecting only variables that were significant within the larger main model. Beta regressions were used to account for the bounded nature of proportion data, which were transformed away from 0 and 1 using the formula $(y *(n-1)+0.5) / n$, where $n$ is the sample size (Smithson \& Verkuilen, 2006). Our beta regressions were run using the betareg package in $\mathrm{R}$ (Cribari-Neto \& Zeileis, 2010).

Before running the model, we tested to ensure that the assumption of multicollinearity was not violated using variance inflation factor analysis. Multicollinearity was detected between the two measures of surrounding environmental complexity, SA and rugosity, so only SA was included in the model. This was chosen over rugosity because SA of the focal colony was more important than focal coral rugosity. After running out main beta regression, we ran a general linear model of the number of non-focal mid-water residents against surrounding habitat SA to identify whether there may have been any indirect effects of surrounding habitat complexity on the proportion of damselfish emerged from the colony. Time of day was not included in the analysis after model weights, AIC values and delta values indicated that time of day did not improve the model. During the post hoc analysis, we removed colony 31, filmed during flowing tide, because it had a disproportionate leverage on the results with a Cook's distance of 0.93 , which exceeds the cut-off of 0.18 set by taking $4 /(n-k-1)$, where $n$ is the sample size and $k$ is the number of predictors in the model (Bollen \& Jackman, 1985).

\section{Results}

We first compared all fixed factors of interest at flowing or slack tide. There were no significant differences in humbug colony group size $(t=1.10$, d.f. $=48, P=0.05)$, focal coral SA $(t=-1.15$, d.f. $=48, P=0.26)$, focal coral rugosity $(t=0.67$, d.f. $=48, P=0.51)$, abundance of non-focal mid-water resident fish $(t=0.13$, d.f. $=48, P=0.9)$, abundance of benthic resident fish $(t=1.54$, d.f. $=48, P=0.13)$, abundance of mid-water nonresident fish $(t=-1.41$, d.f. $=48, P=0.17)$, or local habitat complexity (SA) $(t=0.25$, d.f. $=48, P=0.80)$ between colonies filmed at slack tide and colonies filmed at flowing tide.

\section{Main model}

Analysis of damselfish behavior indicated that focal coral SA was significantly related to damselfish behavior regardless of tide (see Table 1). As focal coral SA increased, so too did the proportion of the colony outside the coral (Fig. 2). There was no effect of focal coral rugosity on emergence behavior, which might relate to how relevant each measure is to refuge availability. With damsels consistently occupying branching corals, the depth or intricacy of the branches may have less bearing on refuge availability than the size or SA of the coral. The model also revealed a significant interaction between tide and the number of non-focal mid-water residents. After running beta regressions with tidal categories, we found that the external social environment did not impact damselfish emergence at slack tide (Beta regression: Estimate $=-0.03, \quad \mathrm{SE}=0.02$, $P=0.07$ ), but had a positive relationship on the proportion of the colony emerged at flowing tide (Estimate $=3.07$, $\mathrm{SE}=0.05, P=0.008$, see Fig. 3).

Although local habitat complexity was not a significant predictor, there was a significant correlation between local habitat complexity and the number of non-focal mid-water resident fish, with more complex environments hosting more mid-water residents (GLM: $F_{1,47}=11.54, P<0.002$, confidence interval $=0.005,0.018$, Adjusted $R^{2}=0.2$, see Fig. 4).

\section{Discussion}

Here, we show that humbug damselfish utilize cues from both the physical and the social environment (i.e. group size), although the relative importance of the external social environment changes according to tide. Our results demonstrate an ability to prioritize foraging behavior when flowing tides bring food past the colony and when the external social environment offers greater protection against predation. Conversely, damselfish showed no change in emergence behavior at low tides when food resources are typically less abundant, showing a greater willingness to forgo foraging as the payoff of this behavior decreased. Furthermore, damselfish colonies 
Table 1 Output from a beta regression examining the effect of the number of non-focal mid-water resident fish, the number of nonresident midwater fish, the number of non-focal benthic resident fish, the surface area (SA) of the focal coral, the rugosity of the focal coral, local group size and surrounding habitat complexity on median proportion of group outside the coral depending on tide

\begin{tabular}{|c|c|c|c|c|c|c|}
\hline & \multirow[b]{2}{*}{ Estimate } & \multirow[b]{2}{*}{ SE } & \multicolumn{2}{|l|}{ Conf Int } & \multirow[b]{2}{*}{$z$ Value } & \multirow[b]{2}{*}{$P$ value } \\
\hline & & & Lower & Upper & & \\
\hline (Intercept) & -1.075 & 1.587 & -4.185 & 2.034 & -0.678 & 0.498 \\
\hline No. mid-water resident fish & 0.117 & 0.053 & 0.013 & 0.222 & 2.195 & 0.028 \\
\hline Tide & 0.087 & 2.386 & -4.591 & 4.764 & 0.036 & 0.971 \\
\hline No. mid-water nonresident fish & 0.053 & 0.07 & -0.084 & 0.19 & 0.762 & 0.446 \\
\hline No. benthic resident fish & 0.077 & 0.06 & -0.04 & 0.194 & 1.291 & 0.197 \\
\hline Focal coral SA & 3.04 & 1.344 & 0.407 & 5.674 & 2.262 & 0.024 \\
\hline Focal coral rugosity & 0.098 & 0.2 & -0.295 & 0.491 & 0.488 & 0.626 \\
\hline Group size & -0.11 & 0.083 & -0.274 & 0.053 & -1.324 & 0.186 \\
\hline Surrounding environmental SA & -0.012 & 0.372 & -0.741 & 0.718 & -0.032 & 0.975 \\
\hline (No. mid-water resident fish)*Tide & -0.14 & 0.061 & -0.259 & -0.02 & -2.292 & 0.022 \\
\hline (No. mid-water nonresident fish)*Tide & -0.057 & 0.071 & -0.196 & 0.083 & -0.8 & 0.424 \\
\hline (No. benthic resident fish)*Tide & -0.04 & 0.084 & -0.205 & 0.125 & -0.474 & 0.635 \\
\hline (Focal coral SA)*Tide & -1.102 & 1.877 & -4.78 & 2.576 & -0.587 & 0.557 \\
\hline (Focal coral rugosity)*Tide & -0.189 & 0.267 & -0.713 & 0.334 & -0.709 & 0.478 \\
\hline (Group size)*Tide & 0.138 & 0.093 & -0.044 & 0.32 & 1.488 & 0.137 \\
\hline (Surrounding environmental SA)*Tide & 0.285 & 0.529 & -0.752 & 1.321 & 0.538 & 0.591 \\
\hline
\end{tabular}

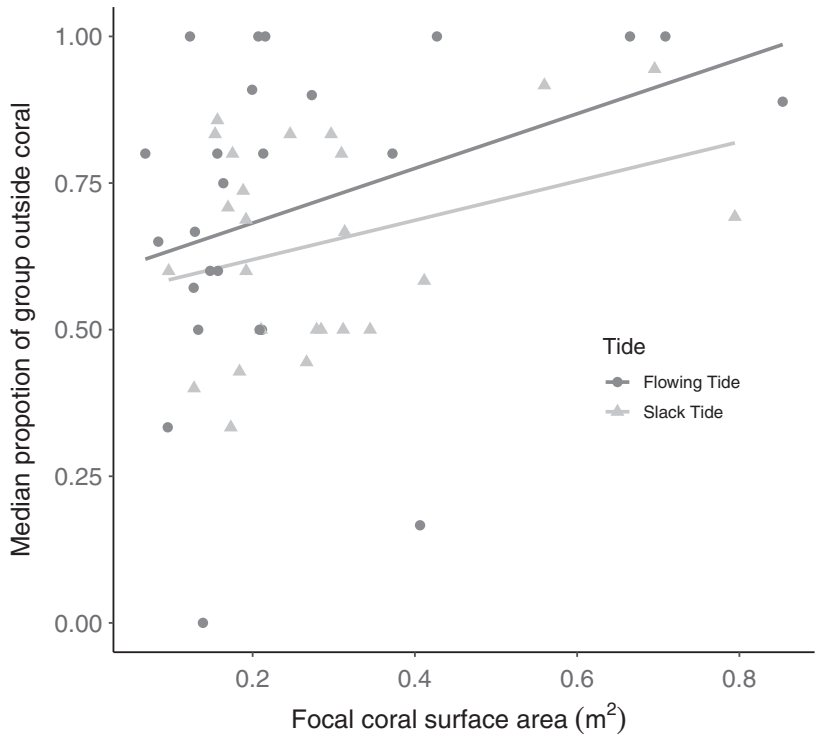

Figure 2 Median proportion of damselfish outside the focal coral as a function of focal coral surface area and tide (light grey triangles: slack low tide, dark grey circles: flowing tide).

occupying smaller focal corals showed more risk averse behavior across both tidal categories.

This importance of focal coral size across both tidal categories speaks to the importance of local refuge availability on risk perception. Whereas many reef fish utilize structures across the reef as refuge from predation, damselfish are highly site-attached meaning that focal coral size is more important than surrounding habitat complexity in determining the availability of predator refugia. Accordingly, we found no direct impact of surrounding habitat complexity on damselfish behavior. However, the strong correlation between surrounding habitat complexity and the abundance of non-focal mid-water residents may indicate that there is an indirect effect of habitat complexity on damselfish behavior. Namely, those complex environments attract more heterospecific mid-water residents, whose behavior may influence the risk perception in damselfish.

This reduced risk perception may relate to the reduced percapita risk associated with the dilution and confusion effects (Ward \& Webster, 2016). However, it may also relate to the benefits of enhanced vigilance, with many eyes increasing the likelihood of detecting a predator (Godin, Classon \& Abrahams, 1988; Ward et al., 2011), as well as access to social information within mixed-species assemblages (Goodale et al., 2017; Webster \& Laland, 2017). In highly social environments, conspecifics and heterospecifics alike can act as an alarm system when shared predators approach, thereby increasing survival success. This has been found in coral reef fish, which can learn predator recognition after a single conditioning event with a heterospecific (Manassa, McCormick \& Chivers, 2013), as well as monkeys, that show improved predator detection despite reductions in per-capita vigilance (Wolters \& Zuberbühler, 2003). This ready uptake of social information is likely to be an important mechanism for increasing survival in such diverse environments. However, it is interesting to note that resident benthic species had no impact on humbug damselfish behavior or their perception of risk. This may indicate a limit to the benefits of mixed-species assemblages with information transfer existing only between species who share ecological or foraging niches or between those vulnerable to the same predators (Pollock, Pollock \& Chivers, 2006; Mitchell, Cowman \& McCormick, 2012).

As damselfish leave the safety of their coral, their exposure to predation increases (James, Bennett \& Krause, 2004). This 


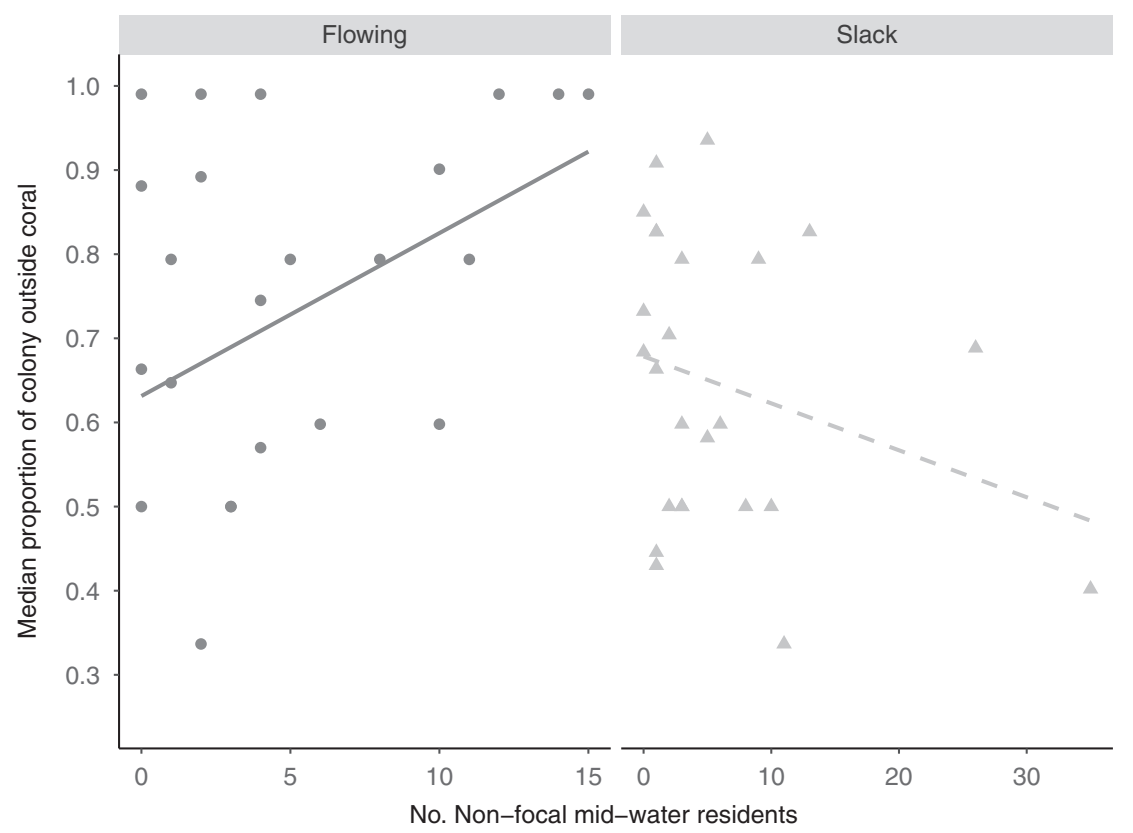

Figure 3 Median proportion of damselfish outside of the focal coral as a function of how many non-focal mid-water residents were counted within $2 \mathrm{~m}$ of focal coral when the tide was slack low (light grey triangles) or flowing (dark grey circles). The dotted trend line is shown despite the nonsignificant relationship between mid-water residents and proportion of damselfish emerged at slack low tide.

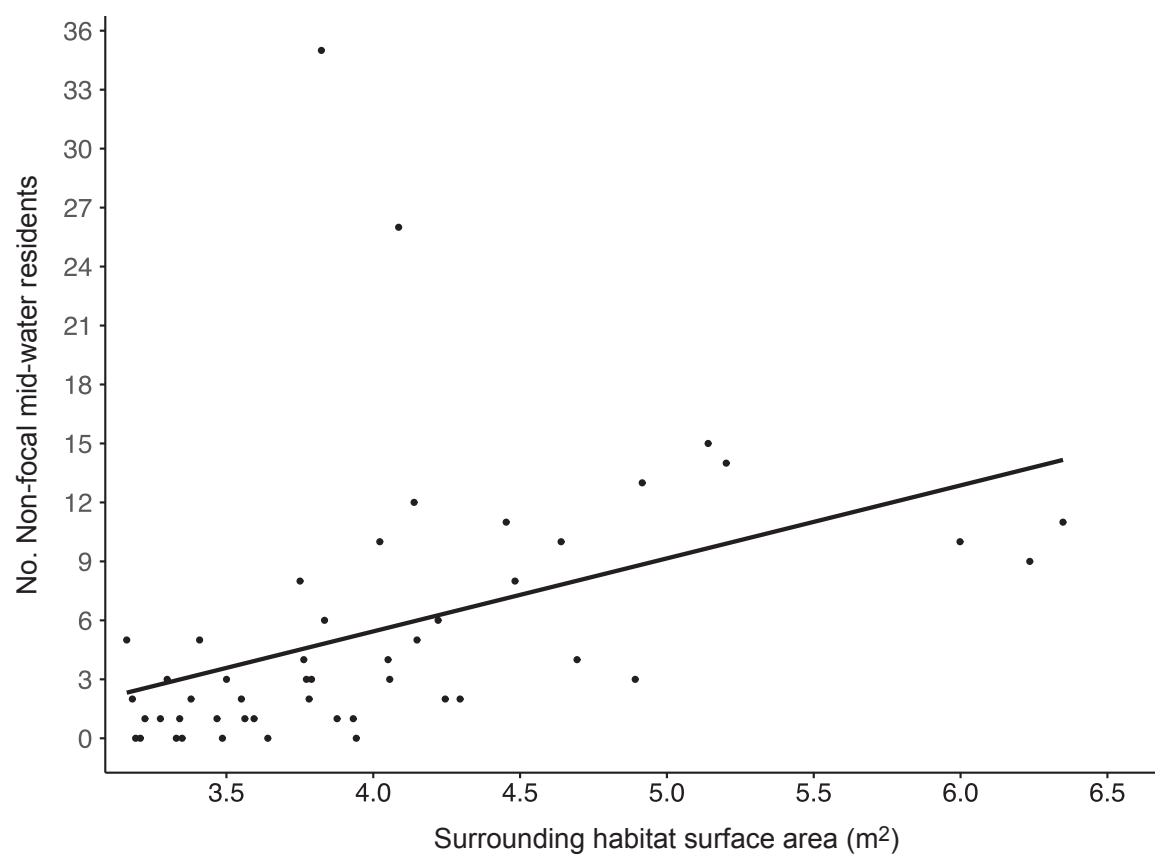

Figure 4 Local habitat complexity against the number of non-focal mid-water residents within $2 \mathrm{~m}$ of focal coral.

may be especially pertinent at flowing tides when the abundance of predators increases (McClanahan \& Muthiga, 1989). Accordingly, we found a shift in the importance of the external social environment at flowing tides with more damselfish emerging to forage as the number of mid-water residents increased. This greater emergence may also be due to the increased flow of plankton past the colonies when water is flowing (Russo, 1977), indicating a greater benefit to emerging. Our results may indicate that damselfish balance the increased risk of emergence at flowing tides by emerging only as the 
external social environment, or number of non-focal mid-water residents, provided greater protection.

A surprising outcome of the current study was the significant effect of external social environment, but not the local social environment, on damselfish emergence patterns. This may suggest that the most important interaction network is the abundance of ecologically similar fish in the vicinity of the home coral rather than the number of colony members. Despite larger groups of conspecifics often conferring antipredator benefits, this may be limited in damselfish due to the hierarchical structure of their colonies, which results in differential spatial distribution based on size and rank (Coates, 1980a,b). Larger and more dominant fish tend to swim higher in the water column and further from the focal coral compared to smaller and less dominant individuals (Forrester, 1991). Large disparities in damselfish size may render individuals vulnerable to different suites of predators, while the wide spatial distribution may mean colony members are not always within view of each other. Potentially, damselfish have more to gain from observing ecologically similar neighbours, who may be closer in size or proximity, than taking cues from their colony mates. Ultimately, the hierarchical nature of damsel colonies and the large size disparities between group members may limit the impact or benefit of large local colony sizes on individual behavior.

Overall, our results underscore the flexible use of social and physical information in shaping the trade-off adopted between foraging and refuging behavior. Specifically, we show that damselfish are risk balancers, emerging from the safety of the coral when the tide is flowing and food is more abundant, and when there are more ecologically similar neighbours in the surrounding environment, potentially offering greater protection from predation. Despite many studies highlighting individual factors impacting animal behavior, this study provides important support for the idea that animals can integrate information from multiple sources at once. Our results highlight the multifaceted ways in which both the physical and social aspects of the environment shape risk perception and behavioral decisions. Having established these behavioral patterns, an important avenue for future investigations would be to quantify how predation and food availability vary along circadian and tidal scales and how these in turn interact with the various abiotic and biotic features described here. This would provide valuable insight into the mechanisms driving the patterns described in the current study.

\section{Acknowledgements}

We would like to thank Ainsley and Paul, the managers of One Tree Island Research Station, for all their help.

\section{References}

Beauchamp, G. (2008). What is the magnitude of the group-size effect on vigilance? Behav. Ecol. 19, 1361-1368.

Boland, C.R. (2003). An experimental test of predator detection rates using groups of free-living Emus. Ethology 109, 209222.
Bollen, K.A. \& Jackman, R.W. (1985). Regression diagnostics: an expository treatment of outliers and influential cases. Sociol. Methods Res. 13, 510-542.

Burns, A.L. (2016). Individuality and the social environment: exploring the mechanisms and functions of individual behavioural variation in fish. Doctor of Philosophy Ph.D., University of Sydney.

Clermont, J., Couchoux, C., Garant, D. \& Réale, D. (2017). Assessing anti-predator decisions of foraging eastern chipmunks under varying perceived risks: the effects of physical and social environments on vigilance. Behaviour 154, 131-148.

Coates, D. (1980a). The discrimination of and reactions towards predatory and non-predatory species of fish by humbug damselfish, Dascyllus aruanus (Pisces, Pomacentridae). Ethology 52, 347-354.

Coates, D. (1980b). Prey-size intake in humbug damselfish, Dascyllus aruanus (Pisces, Pomacentridae) living within social groups. J. Anim. Ecol. 49, 335-340.

Cowlishaw, G. (1997). Trade-offs between foraging and predation risk determine habitat use in a desert baboon population. Anim. Behav. 53, 667-686.

Creel, S., Schuette, P. \& Christianson, D. (2014). Effects of predation risk on group size, vigilance, and foraging behavior in an African ungulate community. Behav. Ecol. 25, 773-784.

Cribari-Neto, F. \& Zeileis, A. (2010). Beta regression in R. J. Stat. Softw. 34, 1-24.

Figueira, W., Ferrari, R., Weatherby, E., Porter, A., Hawes, S. \& Byrne, M. (2015). Accuracy and precision of habitat structural complexity metrics derived from underwater photogrammetry. Remote Sens. 7, 16883-16900.

Forrester, G.E. (1991). Social rank, individual size and group composition as determinants of food-consumption by humbug damselfish, Dascyllus aruanus. Anim. Behav. 42, 701-711.

Godin, J.G.J. \& Smith, S.A. (1988). A fitness cost of foraging in the guppy. Nature 333, 69-71.

Godin, J.G.J., Classon, L.J. \& Abrahams, M.V. (1988). Group vigilance and shoal size in a small characin fish. Behaviour 104, 29-40.

Golub, J., Vermette, V. \& Brown, G. (2005). Response to conspecific and heterospecific alarm cues by pumpkinseeds in simple and complex habitats: field verification of an ontogenetic shift. J. Fish Biol. 66, 1073-1081.

Goodale, E., Beauchamp, G. \& Ruxton, G.D. (2017). Mixedspecies groups of animals: behavior, community structure, and conservation. Cambridge: Academic Press.

Hansen, M.J., Morrell, L.J. \& Ward, A.J. (2016). The effect of temporally variable environmental stimuli and group size on emergence behavior. Behav. Ecol. 27, 939-945.

Hansen, M., O’Leary, P. \& Ward, A. (2017). Interactions between Plagiotremus spp., Labroides dimidiatus and their clients: evidence for behavioural niche partitioning. J. Fish Biol. 90, 424-434. 
Helfman, G.S. (1986). Fish behaviour by day, night and twilight. In The behaviour of teleost fishes: 366-387. Pitcher T.J. (Ed.). Boston: Springer

Heymann, E.W. \& Buchanan-Smith, H.M. (2000). The behavioural ecology of mixed-species troops of callitrichine primates. Biol. Rev. 75, 169-190.

James, R., Bennett, P.G. \& Krause, J. (2004). Geometry for mutualistic and selfish herds: the limited domain of danger. $J$. Theor. Biol. 228, 107-113.

Krause, J. \& Ruxton, G.D. (2002). Living in groups. Oxford: Oxford University Press.

Lima, S.L. (1995). Back to the basics of antipredatory vigilance - the group-size effect. Anim. Behav. 49, 11-20.

Lima, S.L. \& Dill, L.M. (1990). Behavioural decisions made under the risk of predation - a review and prospectus. Can. J. Zool. - Revue Canadienne De Zoologie 68, 619-640.

Longland, W.S. \& Price, M.V. (1991). Direct observations of owls and heteromyid rodents: can predation risk explain microhabitat use? Ecology 72, 2261-2273.

Manassa, R., McCormick, M. \& Chivers, D. (2013). Socially acquired predator recognition in complex ecosystems. Behav. Ecol. Sociobiol. 67, 1033-1040.

McClanahan, T.R. \& Muthiga, N.A. (1989). Patterns of preedation on a sea urchin, Echinometra mathaei (de Blainville), on Kenyan coral reefs. J. Exp. Mar. Biol. Ecol. 126, 77-94.

McDonald, N.D., Rands, S.A., Hill, F., Elder, C. \& Ioannou, C.C. (2016). Consensus and experience trump leadership, suppressing individual personality during social foraging. Sci. Adv. 2, e1600892.

Metcalfe, N.B. (1984). The effects of habitat on the vigilance of shorebirds: is visibility important? Anim. Behav. 32, 981-985.

Metcalfe, N. \& Furness, R. (1984). Changing priorities: the effect of pre-migratory fattening on the trade-off between foraging and vigilance. Behav. Ecol. Sociobiol. 15, 203-206.

Mitchell, M.D., Cowman, P.F. \& McCormick, M.I. (2012). Chemical alarm cues are conserved within the coral reef fish family Pomacentridae. PLoS ONE 7, e47428.
Pollock, M.S., Pollock, R.J. \& Chivers, D.P. (2006). Social context influences the antipredator behaviour of fathead minnows to chemical alarm cues. Ethology 112, 801-806.

Powolny, T., Bretagnolle, V., Aguilar, A. \& Eraud, C. (2014). Sex-related differences in the trade-off between foraging and vigilance in a granivorous forager. PLOS ONE 9, e101598.

Russo, A.R. (1977). Water flow and the distribution and abundance of echinoids (genus Echinometra) on an Hawaiian reef. Mar. Freshw. Res. 28, 693-702.

Sale, P.F. (1971). Extremely limited home range in a coral reef fish, Dascyllus aruanus (Pisces: Pomacentridae). Copeia 1971, 324-327.

Siegfried, W.R. \& Underhill, L. (1975). Flocking as an antipredator strategy in doves. Anim. Behav. 23, 504-508.

Smithson, M. \& Verkuilen, J. (2006). A better lemon squeezer? Maximum-likelihood regression with beta-distributed dependent variables. Psychol. Methods 11, 54.

Ward, A. \& Webster, M. (2016). Sociality: the behaviour of group-living animals. Berlin: Springer.

Ward, A.J.W., Herbert-Read, J.E., Sumpter, D.J.T. \& Krause, J. (2011). Fast and accurate decisions through collective vigilance in fish shoals. Proc. Natl Acad. Sci. USA 108, 2312-2315.

Webster, M.M. \& Laland, K.N. (2017). Social information use and social learning in non-grouping fishes. Behav. Ecol. 28, 1547-1552.

Wolters, S. \& Zuberbühler, K. (2003). Mixed-species associations of Diana and Campbell's monkeys: the costs and benefits of a forest phenomenon. Behaviour 140, 371-385.

\section{Supporting Information}

Additional supporting information may be found online in the Supporting Information section at the end of the article

Table S1. Table showing which species were placed into each of our three non-focal fish categories: resident mid-water fish, resident benthic fish and nonresident mid-water fish 